\title{
LÉVI-STRAUSS NO BRASIL: A FORMAÇÃO DO ETNÓLOGO
}

\author{
Fernanda Peixoto
}

Os anos compreendidos entre 1935 e 1938, quando Lévi-Strauss é professor na recém-criada Universidade de São Paulo, não parecem ter despertado a atenção dos intérpretes e historiadores das ciências sociais durante longo período. É, de fato, a partir da década de 80 que se observa uma espécie de resgate dessa história até então "esquecida" . A morte de Fernand Braudel e a volta de Claude Lévi-Strauss ao Brasil, integrando a comitiva do presidente M itterrand, em 1985, são responsáveis por uma série de artigos, no Brasil e na França, articulando os dois personagens e tantos outros que integraram a missão francesa em São Paulo, na década de 30: Pierre M onbeig, J ean Maugüé, Paul Arbousse-Bastide, Roger Bastide etc. Desde então, não foram poucas as publicações, eventos comemorativos, depoimentos e ensaios que assinalaram a importância do Brasil na trajetória e na obra desses (outrora) jovens que se iniciaram profissionalmente em solo brasileiro por meio de aulas e pesquisas.

Sem pretender retomar nos limites deste artigo a história da missão francesa convidada a inaugurar as atividades universitárias em São PauIo, o meu interesse aqui é iluminar o período brasileiro de Lévi-Strauss e mostrar como apesar de breve e, de modo geral silenciado, ele foi fundamental para os desdobramentos de sua futura carreira como etnólogo². A idéia básica é compreender o lugar do Brasil nesse itinerário específico. Mas não só. De modo a ampliar a reflexão, destacarei alguns aspectos para que possamos avaliar o significado da vinda de Lévi-Strauss ao Brasil no contexto francês da época, em uma tentativa de leitura da viagem pelos olhos do viajante. Finalmente, a retomada da cena universitária paulista em seus primórdios, através de Lévi-Strauss, oferece pistas interessantes para pensarmos os contornos assumidos pelas ciências sociais em geral, e pela antropologia em particular, na Universidade de São Paulo. 


\section{A viagem}

É na França que Lévi-Strauss faz sua formação escolar: primeiro em Versalhes, depois em Paris, onde permanece até o baccalauréat. A École Normale Supérieure, meta de certa elite intelectual francesa, está no horizonte de Lévi-Strauss, que se inscreve no curso preparatório para os exames (hypokhâgne) do liceu Condorcet. As dificuldades com o grego e com a matemática, diz ele, fazem-no optar pelo Direito, na Faculdade de Paris, e, simultaneamente, pela filosofia, na Sorbonne. A pós a agrégation, em 1931, cumpre serviço militar em Estrasburgo e no M inistério da Guerra. Recém-casado, assume o posto de professor no liceu M ont-deMarsan, em 1932.

O período escolar de Lévi-Strauss esteve fortemente marcado pela militância política: foi secretário do grupo de estudantes socialistas das cinco escolas normais superiores (embora não fosse normalien) e secretário-geral da Federação dos Estudantes Socialistas. Nos anos anteriores à agrégation, chegou a ser secretário de Georges M onnet, deputado socialista. Já agregé em filosofia e professor do curso secundário, a política continuou a ter grande espaço em sua vida. Em M ont-de-M arsan, por exemplo, candidatou-se por ocasião das el eições municipais (Eribon e Lévi-Strauss 1990).

A nomeação seguinte é para Laon, onde permanece pouco mais de um ano como professor, embora residindo em Paris, onde prossegue com as atividades políticas. No início de 1935 vem para o Brasil com Fernand Braudel, J ean Maugüé, Pierre M onbeig e outros, integrando a segunda leva de professores franceses contratados pela Universidade de São Paulo. O contexto da vinda para o Brasil foi várias vezes descrito por LéviStrauss em depoimentos e trabal hos de cunho autobiográfico. As versões são concordantes e lidas em conjunto permitem uma visão detalhada do ocorrido.

“M inha carreira se decidiu num domingo de outono de 1934, às 9 horas da manhã, através de um telefonema. Era Célestin Bouglé, então diretor da École Normale Supérieure; ele me tratava desde alguns anos com uma benevolência um pouco longínqua e reticente: em primeiro lugar, porque eu não tinha sido 'normalista', em seguida e sobretudo porque, mesmo que o tivesse sido, não pertenceria ao seu grupo, pelo qual ele manifestava sentimentos muito exclusivos; sem dúvida, não havia ninguém melhor, pois me perguntou abruptamente: - continua com a intenção de se especializar em etnografia? - Certamente! — Então apresente sua candidatura como pro- 
fessor de sociologia da Universidade de São Paulo. Os arrabaldes estão repletos de índios, o senhor poderá dedicar-Ihes os seus fins de semana" (Lévi-Strauss 1957:43).

As palavras um tanto irônicas dirigidas a Bouglé nesta passagem dos anos 50 serão atenuadas em fins de 80 . Afinal, foi Bouglé quem se dispôs a orientar o mémoire d'études supérieures do jovem Lévi-Strauss, que pretendia discorrer sobre os postulados filosóficos do materialismo histórico. Portanto, era natural que conhecesse as aspirações de seu orientando em se tornar etnólogo (Eribon e Lévi-Strauss 1990:25-26).

A etnologia nos anos 30 adquire certa visibilidade no meio intelectual francês, atraindo figuras de formações distintas, de filósofos a escritores. E o caminho mais aconsel hável para um candidato a etnólogo que não houvesse freqüentado os cursos de $\mathrm{M}$ arcel Mauss na École Pratique des Hautes Études era uma viagem, uma experiência de trabalho de campo. A vaga de professor de sociologia parecia, então, um bom pretexto para o jovem filósofo que desejava iniciar-se no ofício, mesmo que este só pudesse ser exercitado nos finais de semana ou durante as férias escolares, já que a USP exigia, contratualmente, dedicação exclusiva à docência.

Para além das questões pessoais envolvidas em toda escolha, a opção pelo Brasil deve ser entendida no contexto intelectual da época, em que o leque de ofertas para um jovem aspirante a etnólogo na França indicava poucos caminhos. M omento de fortalecimento da disci plina em moldes acadêmicos e de profissionalização de seus praticantes, a década de 30 conhece o incremento de algumas vocações (o africanismo, por exemplo) e o surgimento, ainda tímido, de outras (o americanismo). Olhemos mais de perto para a cena francesa do período, e para a maneira como Lévi-Strauss vai ao poucos se encaixando nela, antes de procedermos ao acompanhamento de seus passos no Brasil.

\section{A partida: o contexto francês resumido}

A etnologia francesa, como é sabido, não nasce com Durkheim, nem se desenvolve exclusivamente em torno do grupo durkheimiano. Desde o começo do século XIX, várias missões científicas são organizadas com o objetivo de conhecer os "povos exóticos": as civilizações afro-asiáticas e ameríndias. M as trata-se, de modo geral, de iniciativas extra-acadêmicas patrocinadas por mecenas e ligadas às sociétés savantes da época, como, 
por exemplo, a société asiatique (1822) e a société des américanistes (1895). Isso sem mencionar as informações etnográficas regularmente trazidas por funcionários das colônias francesas, como oficiais, médicos, missionários, dentre outros (Karady 1988), ou, ainda, a reflexão sobre o "primitivo" que teve lugar na "Sociedade dos Observadores do Homem" do século XVIII (Clastres 1983; J amin e Copans 1994). É evidente que na busca das "origens" poderíamos retroceder ainda mais e chegar aos viajantes que desde o século XVI trouxeram informações valiosas sobre os povos primitivos e os países exóticos. M as o objetivo aqui não é pensar a etnologia de modo geral, rastreando as suas raízes, e sim reunir alguns elementos que nos permitam pensar a sua estruturação como disciplina acadêmica organizada institucionalmente na França.

Desde o final do século passado, o grupo durkheimiano aumenta o seu prestígio nas ciências sociais francesas. É o que se verifica, por exemplo, pela ampliação de seu espaço de atuação dentro e fora da universidade. Mais especificamente, após a criação do Année Sociologique, em 1898, o interesse pela etnologia aparece de modo claro: é significativo o número de artigos dedicados aos povos primitivos e à literatura etnográfica na revista, muitos de autoria do próprio Durkheim. Isso sem falar em seu trabal ho de cunho mais antropológico, Les Formes Élémentaires de la Vie Réligieuse (1912), e em seus famosos ensaios, "La Prohibition de I'Inceste et ses Origines" (1898) e "De Quelques Formes Primitives de Classification: Contribution à l'Étude des Représentations Collectives", em parceria com Mauss (1903).

Embora o ensino oficial do M useu de História Natural e da Escola de A ntropologia de Paris possuísse um amplo raio de ação dentro e fora da França, será com os colaboradores de Durkheim que a disciplina entrará no programa universitário francês, a partir da criação do Institut d'Ethnologie da Universidade de Paris, em 1925, e passará a engrossar as fileiras do Collège de France, com a cadeira ocupada por M auss, em 1935. É verdade que M auss, Hubert e Hertz já haviam garantido um ensino mais especializado em antropologia na École Pratique des Hautes Études, porém seus cursos encontravam-se à margem dos ciclos de estudos regulares da universidade, não conferindo ao aluno um certificado, o que só ocorrerá a partir de 1925.

O Institut d'Ethnologie da Universidade de Paris, fundado por Mauss, Lévy-Bruhl e Rivet, pode ser considerado uma espécie de divisor de águas na história da disciplina. Ao patrocinar pesquisas empíricas, formando profissionais, o Instituto passa a atrair novos candidatos para a área. Se antes da Primeira Guerra M undial os cursos tinham poucos alu- 
nos (de 1901 a 1911, o número de alunos nos cursos de M auss variava entre 16 e 38, e no curso de Hubert, entre 10 e 29), no Instituto constavam 26 inscritos em 1926 e 258 em 1938. Entre 1926 e 1940, por exemplo, 113 alunos foram enviados ao campo (Karady 1988: 33)3.

Em relação à pesquisa é importante lembrar que os anos 30 assistem à entrada da Fundação Rockefeller no país, financiando investigações, o que anteriormente era feito por iniciativa privada e estatal em escala reduzidíssima (M azon 1985). A ajuda fornecida pelos novos recursos altera o perfil da disciplina e permite a realização das primeiras grandes experiências de campo da antropologia francesa: a missão Dakar-Djibouti (1931) e a missão Saara-Sudão (1935).

A questão do trabalho empírico na França é ponto importante e controverso entre os historiadores da disciplina. A pesquisa de campo ocupou, de certa forma, lugar secundário na sociologia francesa até os anos 30, o que pode ser em parte explicado pela proximidade da disciplina com uma certa tradição filosófica no país e também pela escassez de recursos. Se a afirmação em linhas gerais é verdadeira - Durkheim é sociólogo "de gabinete”, assim como Lévy-Bruhl e M auss -, é preciso lembrar que tal tradição foi constantemente contestada, seja por M aurice Leenhardt ou por Van Gennep, seja pela escola de M arcel Griaule (Clifford 1988). M as o curioso é que tais pesquisadores foram formados e orientados para a pesquisa pelos mestres "de gabinete", com exceção de Van Gennep que desenvolve o seu trabalho ligado à discussão com os folcloristas sobre questões de cultura popular (Cuisinier e Segalen 1986). Se Leenhardt é um caso particular - já que realizou suas primeiras experiências de campo como missionário - , foi a amizade com M auss e LévyBruhl que o introduziu na carreira de etnólogo. Os membros da missão à África, por sua vez, foram em sua maioria alunos de M auss, referindo-se com freqüência aos seus consel hos e cursos ${ }^{4}$.

As missões francesas à Á frica tiveram grande importância não só porque por seu intermédio foi formada uma geração de pesquisadores, moldando um novo perfil da etnologia em contexto francês, mas também porque inauguraram uma área temática, uma nova "vocação" : o africanismo.

Dirigida por M arcel Griaule e contando com a participação, entre outros, de Michel Leiris e de André Schaeffener, a missão Dakar-Djibouti (1931-1933) é a primeira a abrir as portas da África aos pesquisadores franceses. Projetada como uma grande pesquisa extensiva, que deveria cobrir um itinerário de cerca de 20 mil km, a missão previu também pesquisas em profundidade a serem realizadas em algumas regiões: $M$ ali, norte de 
Camarões e região etíope de Godjan (Caltagirone 1988). Em 1935, uma nova missão é organizada com o objetivo de completar os dados e as coleções etnográficas recolhidos pela missão Dakar-Djibouti: a missão SaaraSudão. Griaule, nesse momento, recolhia material para a conclusão de seu trabalho sobre as máscaras dogon (tese apresentada em 1937), enquanto a lingüista Deborah Lifchitz realizava uma investigação mais sistemática sobre a língua dogon e Denise Paulme, jurista de formação, pesquisava a organização social do grupo. Graças a uma bolsa da Fundação Rockefeller e ao apoio de Rivet e Lévy-Bruhl, as pesquisadoras prolongaram sua estada no país dogon por mais seis meses - de março a setembro de 1935. Este período ficou conhecido como a "missão Paulme-Lifchitz" e se caracterizou por um trabalho mais intensivo que os anteriores (Dupuis 1987).

$\mathrm{O}$ africanismo conhece um surto expansionista nos anos 30, embora o interesse pela África, como sabemos, seja muito anterior (Duchet 1977). Em 1931, quando é criada a Société des Africanistes, a curiosidade pela cultura africana é compartilhada por setores mais amplos da sociedade francesa. Os surrealistas, por exemplo, incorporam o africano - efetivamente o "outro" desvendado pela antropologia francesa - em sua crítica cultural. Os elementos do mundo negro passam nesse momento a impregnar a vida parisiense - música, imprensa, exposições de objetos africanos - e se tornam fonte de inspiração para diversas obras produzidas no período (Clifford 1981).

A aproximação da etnologia ao mundo das artes na França, dada principalmente pelo grupo surrealista, produz uma série de resultados interessantes, como por exemplo a revista Documents, editada por Georges Bataille a partir de 1929, que dedica um número inteiro à missão Dakar-Djibouti; ou o catálogo da exposição Les Arts A nciens de l'A mérique, organizada por Georges Henri-Rivière em 1928, para o qual Bataille escreve "L'A mérique Disparue". A posição anticolonialista dos surrealistas mobiliza o interesse pelos povos colonizados e leva vários de seus partidários a escreverem textos de caráter etnológico. M as tal posição, longe de significar apenas uma bandeira política - que outros também levantaram -, tem um sentido mais profundo no interior da "filosofia" surrealista. Ferozes e irreverentes críticos do ponto de vista antropocêntrico, os membros do grupo compartilham a conviç̧ão acerca da necessidade de ampliação das fronteiras do humano. Nesse sentido, o homem não poderia mais ser pensado sem os seus "outros", sem os seus "duplos": os animais, as figuras monstruosas, os primitivos (M oraes 1996:109).

M ichel Leiris é um personagem emblemático para pensarmos a íntima articulação entre etnologia e arte no período. Afinal, ele é um poeta 
de feição surrealista que faz a opção pela etnologia, e isto não significa rupturas. Ao contrário, basta acompanharmos a produção do autor para percebermos que seus livros etnológicos se encontram perfeitamente integrados ao conjunto de sua produção (Peixoto M assi 1992). O interesse pela etnologia, ele não se cansa de afirmar, nasceu com o surrealismo e representava a rebelião contra o racionalismo ocidental, que se traduzia na curiosidade pelos povos primitivos e pela "mentalidade primitiva" (J amin e Price 1988).

O americanismo conhece desenvolvimento distinto na França. Embora organizado precocemente sob a forma de uma société savante a Société des Américanistes é fundada em 1895 - , nos anos 30 é ainda uma área pouco explorada, sendo Georges Henri-Rivière, do M useu de Artes e Tradições Populares, e Paul Rivet, do Museu do Homem, seus mais destacados representantes.

A Sociedade dos A mericanistas é criada com a ajuda financeira do conde de Loubat, seu presidente de honra, e tem como diretor o professor E.-T. Hamy, do M useu de História N atural. Segundo os estatutos, seu objeto é o "estudo histórico e científico do continente americano e de seus habitantes desde as épocas mais remotas até os nossos dias". Seus membros editam, desde o primeiro ano de existência da Sociedade, uma revista cujo conteúdo apresenta "todos os documentos próprios para se conhecer os progressos das ciências americanas". O americanismo é definido pelos seus praticantes como uma ciência - que compreende as diversas disciplinas mencionadas - voltada para o conhecimento das Américas, e cuja questão central, norteadora das investigações, diz respeito às origens americanas.

A companhando a publicação desde o momento de sua criação até 1940 - corte cronológico que me permitiu seguir os passos de LéviStrauss em direção ao grupo dos americanistas -, é possível perceber duas fases, que correspondem a dois momentos distintos das pesquisas sobre as A méricas. A primeira, que se estende até meados dos anos 20, caracteriza-se por ser um período auto-referente, quando o J ournal fala preferencialmente de si próprio, da Sociedade e de seus membros, que são os mais assíduos colaboradores da publicação. O segundo momento, que tem início em finais dos anos 20 e começo da década de 30, está marcado pela entrada em cena dos especialistas, formados nas faculdades da época, que divulgam os resultados de suas primeiras investigações. Os viajantes, grandes responsáveis até então pelas informações sobre as A méricas, cedem lugar aos "novos americanistas" : Alfred M étraux, que em 1926 estréia na publicação com um artigo sobre as migrações históri- 
cas dos Tupi-Guarani; J ean Vellard, que assina em 1934 o primeiro de uma série de artigos sobre os Guayaqui; J acques Soustelle, que divulga suas pesquisas com as populações mexicanas a partir de 1935; LéviStrauss, autor de um longo artigo sobre os Bororo, em 1936.

O lugar ocupado pelo Brasil no J ournal até os anos 30 é bastante discreto. Além de poucos artigos - sobretudo informações de viagens -, o país aparece com maior freqüência na seção N ouvelles et mélanges américanistes, onde são noticiados: viagens feitas em território brasileiro, parte da produção dos museus (Museu Paraense e Paulista), recenseamentos populacionais e fatos políticos. No final da década de 20 , será Paul Rivet o principal cronista da situação brasileira no âmbito da publicação ${ }^{5}$. Os anos 30 , como vimos, assistem a um maior número de missões etnológicas organizadas na França, o que pode ser perfeitamente acompanhado pela leitura do J ournal de la Société des A méricanistes. Comparando, porém, as investigações realizadas na Ásia, África e A mérica, fica evidente o predomínio dos estudos africanos no período. As populações inscritas em território brasileiro nessa época são praticamente desconhecidas; é possível contar nos dedos as pesquisas realizadas sobre elas: em 1929, J ean Vellard faz uma viagem do Rio de J aneiro ao Pará, atravessa o Araguaia e realiza um estudo sobre os Carajá; em 1936, Dina e Claude Lévi-Strauss passam um período entre os Bororo e, em 1938, acompanhados por Vellard, realizam uma visita aos índios do M ato Grosso6.

O J ournal de la Société des A méricanistes acompanha os passos do jovem etnólogo. Em 1935, Rivet publica a seguinte nota: “M. Claude LéviStrauss, professor na Faculdade de Letras, Ciências e Artes (sic) de São Paulo e sua mulher foram encarregados de missão pelo M inistério de Educação Nacional para estudarem de perto algumas tribos pouco ou mal conhecidas no M ato Grosso. M. Lévi-Strauss apresentou ao conselho da Universidade de São Paulo um projeto de fundação de um Instituto de Antropologia Física e Cultural" (J ournal de la Societé des A méricanistes XXVII:475-476). No momento mesmo em que esse comunicado aparece nas páginas da publicação, o nome de Lévi-Strauss passa a constar na relação de membros da Sociedade dos Americanistas.

Em 1936, Lévi-Strauss publica o seu primeiro artigo no J ournal: "Contribution à l'Étude de l'Organisation Sociale des Indiens Bororo" (Tomo XXVIII). Trata-se do primeiro resultado de suas pesquisas editado em um veículo de renome internacional. Com ele, desloca-se da seção Mélanges, onde eram divulgadas as suas viagens pelo Brasil, e passa ao local nobre da publicação, ao lado de Soustelle e M étraux. 
No mesmo ano e volume, Soustelle anuncia as "novas pesquisas no Brasil":

“N o começo do mês de março vol tam a São Paulo M. e M me. Lévi-Strauss, que estiveram entre os Kaduveo e os Bororo. Eles encontraram a primeira população em um estado de degradação avançado. Dentre 150 Kaduveos aproximadamente, apenas 20 descendem de pai e mãe índios. Entretanto, sua cultura material e instituições parecem ter conservado uma certa originalidade. Totalmente diferente é a situação dos Bororo, cuja cultura material e instituições se mantiveram praticamente intactas. M. e M me. Lévi-Strauss tiveram a sorte de assistir a um número considerável de cerimônias que puderam filmar e centraram seus estudos na organização clânica e nas classes matrimoniais" (J ournal de la Société des Américanistes XXVIII:262).

Nos anos seguintes, Dina Lévi-Strauss publica duas notas informativas: a primeira sobre a Sociedade de Etnografia e Folclore do Departamento de Cultura de São Paulo (Tomo XXIX) e a outra sobre a "missão Vellard-Lévi-Strauss", de 1938 e 1939 (Tomo XXX).

Como se faz um americanista, poderia ser o subtítulo dos três parágrafos anteriores. A experiência de campo - condição sine qua non para a formação do especialista - é o que permite a Lévi-Strauss ter acesso ao grupo. Feita a iniciação, torna-se um igual, passando a integrar uma nova rede: a Sociedade, of ournal, os congressos. Esse circuito específico reúne arqueólogos, folcloristas, geógrafos, viajantes e, sobretudo, etnólogos sob uma mesma legenda. O que os unifica, fundamentalmente, é o estudo da(s) América(s), de sua paisagem, história, tipos humanos, organizações sociais. Com esse objetivo, tais pesquisadores circulam por diferentes países, cruzando fronteiras, desenhando recortes: o mapa que têm diante de si é o da A mérica. Os contornos nacionais, nesse caso, não estão em destaque. Por isso, antes de qualquer outra alcunha que possam ter recebido no futuro - mexicanistas, brasilianistas etc. - são, acima de tudo, americanistas. As palavras de Viveiros de Castro são exemplares: “É importante observar que 'americanista' não é um gênero de que 'brasilianista' (por exemplo) seria uma espécie. N ossas espécies são antes coisas como 'andinista', 'mesoamericanista', 'especial ista nos índios do sudoeste norte-americano', 'amazonista' e variedades informais do tipo 'tupinólogo', 'jivarólogo' ou 'esquimologista'” (1990:3). 


\section{No Brasil}

Lévi-Strauss chega ao Brasil em 1935, após ter tido o seu nome aprovado por Georges Dumas7 , de quem havia sido aluno em Saint-Anne. A viagem é feita na companhia de J ean Maugüé, Fernand Braudel, Pierre Monbeig e Dina, etnóloga e esposa do jovem filósofo. Claude LéviStrauss deveria ocupar a cadeira de sociologia da seção de ciências sociais da Faculdade de Filosofia, Ciências e Letras, onde se encontrava, desde 1934, Paul Arbousse-Bastide.

Recepcionados por J úlio de M esquita no cais em Santos, os professores foram levados provisoriamente para o Hotel Termidor, no centro de São Paulo. M as "como ganhavam bem, não demoraram a encontrar um local fixo de moradia. Lévi-Strauss alugou uma casa na rua Cincinato Braga, a poucos quarteirões da avenida Paulista; Paul Arbousse morou primeiro na Av. Brasil e depois no Brooklin; M augüé manteve-se hospedado no Hotel Esplanada, perto do Teatro Municipal" (Schaden 1990).

Nos depoimentos dos ex-alunos da Faculdade de Filosofia da USP, Lévi-Strauss não aparece como professor destacado, digno de referência especial. Em geral, fala-se dele somente quando o seu nome é mencionado, ao contrário de J ean M augüé ou de Roger Bastide, sempre lembrados quando o tema é a história da universidade e a missão francesa (M ello e Souza 1988). De qualquer modo, as recordações são positivas: “Seguir seus cursos era evidentemente alguma coisa de especial. A exposição não era viva mas as idéias, sempre claras. $E$ era sobretudo admirável a sua maneira de fazer trabal har e ler, com exposições, seminários e discussões. Não era um homem conhecido, mas havia muita gente em seus cursos" (Schaden apud Lindon 1988). As aulas eram dadas em francês, já que Lévi-Strauss não chegou a falar português (diz Schaden que Ihe ensinava português, em troca de lições de francês). Além das discussões em sala de aula, o professor, segundo seus alunos, convidava-os periodicamente para um chá em sua casa.

As recordações de Décio de Almeida Prado sublinham a preocupação do professor com a observação direta e com a pesquisa de campo, para as quais orientava os alunos:

“Um dos primeiros trabalhos que nos deu foi proceder a uma análise social da cidade de São Paulo por volta de 1820, tal como aparece nos documentos da época, onde ele identificou quais eram e onde os encontraríamos. Para o curso que fez sobre as leis do parentesco nas sociedades primitivas, em vez de pedir digressões, distribuiu entre os alunos, como exame, uma série de 
árvores genealógicas individualizadas. Fornecia as regras sociais do grupo e indagava com quem se casaria determinada pessoa" (Prado 1997).

Além disso, indica Décio, as aulas do mestre francês primavam pela fluência, pelo encadeamento seguro do raciocínio: "Se alguma coisa aprendíamos era raciocinar. N ão nos perdíamos nem mesmo nas seqüências longas, porque elas se apresentavam bem articuladas, víamos as imbricações" (Prado 1997).

Ainda que ocupasse a cadeira de sociologia, os temas de curso de Lévi-Strauss variavam segundo um amplo leque: de sociologia primitiva à antropologia urbana, passando por lingüística, etnolingüística e antropologia física9. Essa variação, entretanto, não ultrapassava os limites da antropologia. Um programa do ano de 1935 mostra que a sociologia pela qual Lévi-Strauss se interessava se relacionava diretamente com o estudo dos povos primitivos. Tratava-se, segundo registro dos anuários da Faculdade, de um "curso temático sobre as formas elementares da vida social, com o objetivo de apresentar noções sumárias sobre a localização e os caracteres dos principais grupos sociais invocados em sociologia comparada". Os principais tópicos abordados eram: "sociologia doméstica (o casamento, a proibição do incesto, o parentesco, a poligamia, o clã, o matriarcado); a sociologia econômica (as formas primitivas de sociedade, o comunismo primitivo); sociologia política (as formas primitivas de governo e de justiça); sociologia religiosa (o totemismo); e um tópico final discutindo o estudo comparativo dos fenômenos sociais". Como bibliografia básica, quatro clássicos: Les Formes Élémentaire de la Vie Religieuse, de Durkheim; Primitive Society, de Lowie; L'État Actuel du Problème Totémique, de Van Gennep; e Histoire du M arriage, de Wastermarck (A nuário da FFCL-USP 1936: 214,216)10.

O que chama a atenção nos programas de curso dados por LéviStrauss no Brasil é que eles contêm, de modo concentrado, os temas sobre os quais ele irá trabalhar ao longo de sua obra: parentesco, totemismo, mitos. No período de aprendizado de um ofício, ele desenha, de certo modo, um universo de preocupações teóricas e temáticas do qual não mais se afastará.

A lém dos cursos regulares na Universidade, os professores franceses eram obrigados a realizar conferências periódicas, que em geral ocorriam na Faculdade de Direito. Em 1935, temos o registro de cinco palestras de Lévi-Strauss, das quais, infelizmente, não ficaram senão os títulos: "Progresso e retrocesso", "A crise do evolucionismo", "A hipótese evolucionista", "Existem culturas superiores?" e "A caminho de uma 
nova filosofia do progresso". De 1938, mais um título: "Os problemas criados pelo estado atual da etnografia sul-americana". Em 1937, as fontes falam alternadamente de um curso de extensão universitária e de uma conferência sobre um mesmo tema: "Os contos de Perrault e sua significação sociológica". Neste curso (ou conferência), Lévi-Strauss discute o significado dos contos, mostrando como estão repletos de preceitos relacionados a povos primitivos, alguns já desaparecidos. Com o objetivo de comparar mitos e contos, reflete sobre a natureza dos mitos para os primitivos (Anuário da FFCL-USP 1937-1938:72-73).

Seguindo os rastros deixados por Lévi-Strauss durante os três anos passados no Brasil, é possível encontrar além do programa de curso e das conferências mencionadas, al guns artigos publicados em revistas e jornais especializados. Um dos primeiros foi editado na Revista do Arquivo M unicipal, no ano de 1935, sob o título: “O Cubismo e a Vida Cotidiana"11. Tal artigo pode causar espanto aos mais desavisados, mas não destoa, de modo algum, da biografia e da produção de Lévi-Strauss. Bisneto de músico, filho e sobrinho de pintores, Lévi-Strauss cresceu em um meio intimamente ligado às artes. Este contato será reforçado pela intensa convivência com os surrealistas durante a guerra, em N ova Iorque, e continuará pelo resto de sua vida. Max Ernst, André Breton e Patrick Waldeberg, como ele afirma em várias ocasiões, tornaram-se relações permanentes. Se o interesse pelas artes pode ser pinçado em parte significativa da produção do autor (em La Pensée Sauvage, nas M ithologyques, em La Voie des Masques, em Le Regard Eloignée e em vários outros trabaIhos), ele passa à cena principal em publicação mais recente, Regarder, Écouter, Lire (1993). O artigo de juventude não tem como propósito a análise da produção cubista, nem de seus ilustres representantes; quer destacar a importância do movimento na construção de um novo ol har, de uma nova visão de mundo. M ostra o autor como o cubismo infiltrou-se no cotidiano, na publicidade e na arquitetura moderna (Lévi-Strauss 1935a).

A estética e as artes foram objeto de atenção de mais de um dos professores franceses que passaram pelos cursos de filosofia e ciências sociais da USP nas décadas de 30 e 40. Além de Lévi-Strauss, lembremos de J ean Maugüé e Roger Bastide, que além de terem escrito sobre o assunto, incorporaram-no em vários de seus programas de curso. M augüé, mais afeito à "carpintaria teatral" das salas de aula, deixou poucos textos no papel, tendo marcado os alunos, sobretudo, pelo estilo interpretativo e por uma prosa rara (A rantes 1994). Bastide, por sua vez, não apenas escreveu sobre sociologia da arte, mas aproximou-se das manifesta- 
ções artísticas nacionais - populares e eruditas -, como crítico atuante nas páginas dos periódicos locais, e também como pesquisador do folclore e da estética afro-brasileira. Comparando os pronunciamentos e os escritos sobre arte dos três professores, Gilda de M ello e Souza (1990) assinala que se M augüé e Lévi-Strauss permaneceram europeus, apesar do período brasileiro, Bastide abrasileirou-se. Segundo a ex-aluna, enquanto os dois primeiros falavam de pintura tendo como referência exclusiva a Europa, Bastide debruçou-se sobre a realidade brasileira, em um esforço de compreensão de um país sem tradição cultural forte. Nesse sentido, teria sido Bastide o único dos três a elaborar uma "estética pobre".

Outro artigo de Lévi-Strauss, também de 1935, “Em Prol de um Instituto de Antropologia Física e Cultural", é publicado na mesma Revista do Arquivo M unicipal. Como o próprio título indica, trata-se da apresentação de um projeto de criação de um Instituto de Antropologia Física e Cultural que, segundo Lévi-Strauss, deveria ser um lugar reservado à pesquisa antropológica dentro da universidade, nos moldes dos grandes institutos estrangeiros. As pesquisas nas áreas de antropologia física e cultural - esta última deveria ser ainda mais desenvolvida no Instituto, porque mais recente - , pensadas de modo articulado, permitiriam a elaboração de um "Grande Fichário Antropológico A mericano". Feito isso, o Instituto estabeleceria, a partir da classificação de cada rito, crença ou técnica, um grande "Atlas", "no qual mapas do continente americano mostrariam as zonas de distribuição e as variações de densidade" (LéviStrauss 1935b:251-256)12.

Algumas breves observações poderiam ser feitas ao final da leitura do projeto apresentado por Lévi-Strauss. Inicial mente, nota-se que pela primeira vez ele toca na questão racial, ponto que irá desenvolver no célebre Raça e História (1950), e que constitui um problema fundamental para o pensamento social brasileiro do período, objeto privilegiado das pesquisas científicas da época. 0 curioso é que o faça enfatizando o estudo dos caracteres físicos dos negros e dos mestiços: a mestiçagem ofereceria uma possibilidade única para o estudo das leis de hereditariedade do homem. Nesse contexto, cita, inclusive, a "obra admirável" de Roquette-Pinto.

Em segundo lugar, destaca-se no texto a idéia da articulação ensino e pesquisa, da formação de pesquisadores com experiência prática e cursos interdisciplinares. Não seria exagerado dizer que tal plano, precocemente elaborado, se realizou, de forma distinta evidentemente, anos mais tarde, no Collège de France, quando da criação do Laboratoire d'Anthropologie Sociale. Chama a atenção também o interesse pelos estudos com- 
parados: o Brasil deveria ser investigado no contexto americano, já que "a América em geral, e a A mérica do Sul em particular forneceram algumas das mais ilustres civilizações da história, foram o cadinho onde se misturaram algumas das mais importantes correntes culturais" (LéviStrauss 1935b:256).

Do ano de 1936, constam três artigos de Lévi-Strauss: “Contribuição para o Estudo da Organização Social Bororo", publicado na Revista do Arquivo Municipal; "Entre os Selvagens Civilizados”, que apareceu em 0 Estado de S. Paulo e "Os M ais Vastos Horizontes do M undo", integrando os Anuários da Faculdade de Filosofia, Ciências e Letras da USP. O ensaio sobre os bororo é considerado por Lévi-Strauss o único texto relevante de sua produção brasileira, ainda que, segundo ele, estivesse mais próximo do jornalismo do que da etnologia. Foi graças a esse trabalho, publicado no mesmo ano no J ournal de la Société des A méricanistes, segundo ele, que sua posterior ida para os EUA foi garantida (Eribon e Lévi-Strauss 1990:36). Em 1937, a Revista do Arquivo M unicipal divulga a última colaboração de Lévi-Strauss para a publicação antes de sua partida: um artigo irônico intitulado "A Propósito da Civilização Chaco-Santiaguense" 13. O texto relata um debate que teve início com uma resenha de LéviStrauss para o jornal O Estado de S. Paulo (11/4/1937) sobre o primeiro volume da obra dos irmãos Ducan e Emílio Wagner, A Civilização ChacoSantiaguense e suas Correlações com as do Velho e do Novo M undo.

Há referências a outros textos e conferências de Lévi-Strauss realizados no Brasil, no Boletim da Sociedade de Etnografia e Folclore: uma comunicação de 1937 sobre "Algumas bonecas karajá" , a partir de exemplares por ele recol hidos na região do Araguaia, Goiás; e uma conferência sobre "A civilizacão material dos índios Kadiueu" (sic). Não parece estranho Lévi-Strauss ter publicado a maior parte de seus artigos e palestras da década de 30 na Revista do Arquivo M unicipal e no Boletim da SEF. Tanto a revista quanto o boletim eram órgãos oficiais do Departamento de Cultura de São Paulo, dirigido por Mário de Andrade entre 1935 e 1938. Foi M ário quem atraiu o casal Lévi-Strauss, Roger Bastide e Paul A rbousse-Bastide para os projetos culturais e científicos implementados em sua gestão. $M$ as, dentre os estrangeiros, parece ter sido Dina a que mais de perto se envolveu com a SEF, ministrando cursos e secretariando a Sociedade entre 1937 e 1938 (Rubino 1995; Soares 1983). Claude LéviStrauss fazia parte do conselho técnico da Sociedade e foi um dos seus sócios fundadores, ao lado de Paul A rbousse-Bastide e Pierre M onbeig. Aliás, é a municipalidade de São Paulo uma das financiadoras de sua expedição ao Brasil Central, em 1937 e $1938^{14}$. 
A Sociedade, como sabemos, teve vida curta, extinta junto com o Departamento de Cultura pela política do Estado Novo, em 1938. Enquanto durou, foi ela o principal vínculo de Lévi-Strauss com o meio intelectual paulista. M esmo assim, sua participação na instituição resumiu-se a conferências e textos, cabendo a Dina o trabalho de pesquisa, organização e assessoria etnológica. Egon Schaden, por exemplo, quase não se lembra de tê-lo visto nas reuniões periódicas que se realizavam em uma sala lateral do Teatro M unicipal. Segundo ele, a participação dos professores franceses na Sociedade de Etnografia e Folclore foi tímida. Aí, foi Dina a grande atuante.

\section{"O Lévi-Strauss continua atrás dos índios" (Oneida Alvarenga, carta de 13/8/38)}

Em São Paulo, lembra Lévi-Strauss em Tristes Trópicos, podia-se fazer a "etnografia de domingo", não com os índios, "como lhe haviam prometido", mas com alemães, japoneses e negros. Entretanto, na primeira oportunidade, o jovem professor sai ansiosamente em busca de alguns dos “exemplares indígenas" sonhados. No velho Ford de René Courtin, professor de economia na USP entre 1937 e 1938, e na companhia de J ean Maugüé, chega até as margens do Araguaia, em uma cabana Karajá (Lévi-Strauss 1957:119). M augüé relata sua versão do ocorrido:

“Éramos jovens apesar de tudo. Era natural que eu aceitasse com alegria a proposta que fez Lévi-Strauss para que eu o acompanhasse numa viagem aos confins de Goiás para ter contato com os índios. René Courtin devia se juntar a nós. 'A gregé' em direito e professor na faculdade de M ontpellier, ele sucedeu em São Paulo, François Perroux, e parecia tão simples e feliz, ao contrário de seu predecessor, irascível e distante. Ele tinha uma paixão: a caça. Estava fascinado por Lévi-Strauss. A idéia de que os indígenas pudessem obedecer a regras matrimoniais, à matemática mais sutil, deixavam-no sonhador [...]. Lévi-Strauss logo começou a trabalhar, sentado sobre o mesmo solo que os indígenas, procurando se fazer entender, lançando perguntas, tomando notas. Eu me maravilhava vendo que ele podia decifrar gestos dos quais Courtin e eu não podíamos pegar senão o pitoresco" (Maugüé 1982:118-121, tradução minha).

O norte do Paraná foi palco das primeiras incursões de Lévi-Strauss, acompanhando com M onbeig a expansão das zonas pioneiras. $\mathrm{N}$ essas 
terras, finalmente, teve o seu primeiro contato com os índios, às margens do rio Tibagi. Porém, para decepção do etnólogo, "os índios Tibagi não eram nem 'verdadeiros índios', nem ‘selvagens'” (Lévi-Strauss 1957:160161). Depois desse début, estava nosso etnógrafo preparado para aventuras mais ousadas. Estas ocorrem no final do primeiro ano escolar (1935/1936), quando ele e Dina visitam os Kadiveu da fronteira paraguaia e os Bororo, no M ato Grosso Central. Tal viagem valeu ao casal LéviStrauss sua primeira exposição em Paris, nas férias entre 1936 e 1937, na Galeria Wildenstein. A mostra do material recolhido no Brasil foi fundamental para a entrada de Lévi-Strauss no meio etnológico francês, como ele faz questão de afirmar: "Eu precisava fazer minhas provas de etnologia, porque não tinha formação alguma. Graças à expedição de 1936, consegui créditos do M useu do Homem e da Pesquisa Científica, ou do que acabaria chamando-se assim. Com esse dinheiro, organizei a expedição nambiquara" (Eribon e Lévi-Strauss 1990:33-34)15.

A expedição até os Nambikwara foi organizada durante o ano de 1937, e realizada em 1938. Com financiamento francês e brasileiro, a idéia era passar um ano no campo. De fato, a expedição iniciou-se em maio de 1938, terminando, todavia, em novembro do mesmo ano. Dela fizeram parte, além do casal Lévi-Strauss, o médico e etnólogo francês J ean Vellard e o antropólogo brasileiro Luis de Castro Faria, já que as ordens oficiais eram de que deveria haver pelo menos um brasileiro em toda e qualquer missão estrangeira no Brasil. A versão de Castro Faria sublinha os problemas que a missão Vellard/Lévi-Strauss enfrentou com os órgãos públicos no Brasil, já que Lévi-Strauss contou com o patrocínio de Rivet, ligado ao Partido Socialista francês, e que se tornara persona non grata no Brasil por conta de rumores de que teria difamado o país na França (Faria 1984:229)16. Quando foi formalizado o pedido de autorização, novos problemas surgiram, lembra Castro Faria:

\footnotetext{
“Nenhuma expedição estrangeira podia percorrer o Brasil sem autorização do Conselho de Fiscalização das Expedições Artísticas e Científicas, criado desde 1933 (decretos números 22.698, de 11 de maio, e 23.311, de 31 de outubro). Heloisa Alberto Torres, membro destacado do Conselho e amiga de ambos [de Lévi-Strauss e de Rivet], enfrentou e venceu as resistências, ampliadas pelo fato de que o outro membro francês da expedição era igualmente vítima de rumores, com alegações de que havia recebido facilidades do governo paraguaio para lá realizar expedições de estudo e publicara um relatório de viagem com informações desairosas sobre o país. A presença de um membro brasileiro na expedição tornou-se indispensável" (1984:230).
} 
O itinerário da missão (Serra dos Parecis, Mato Grosso), deveria seguir os postos telegráficos da linha Rondon. Dina Lévi-Strauss resume, em ordem cronológica, os trabalhos:

“1) Primeiro contato prolongado com os índios Nambikwara, na região de Utiariti; 2) Visita e permanência numa aldeia nambikwara na região de J uruena; 3) Contatos diversos com frações do mesmo grupo, entre J uruena e Nambikwaras; 4) Na região dos Nambikwara, contato prolongado com frações do mesmo grupo; 5) $\mathrm{Na}$ região de Vilhena, contato prolongado com três subgrupos Nambikwara; 6) No começo de outubro, a expedição chega a Pimenta Bueno. Visita um grupo pertencente à cultura Guaporé, não classificado do ponto de vista lingüístico e representado por cerca de trinta indivíduos; 7) A pós pesquisas longas e difíceis, permanência numa aldeia Tupi, situada a meio caminho entre Presidente Hermes e Presidente Pena. Este grupo, muito pobre e culturalmente degenerado, foi entretanto objeto de frutífera enquête; 8) No final de novembro, a missão, tendo chegado a Presidente Pena, encontrou-se impossibilitada de retomar a sua vida normal para o sul, em razão das chuvas torrenciais, do estado sanitário de seus membros etc. Ela decidiu então a saída pelo norte, em direção ao rio M adeira, depois para o oeste e para a Bolívia" (J ournal de la Société des Américanistes, Tomo XXX:384-386).

A missão Lévi-Strauss visitou também os Bororo e os últimos representantes dos Tupi-Kaguahib do rio M achado, considerados desaparecidos, relata Lévi-Strauss em Tristes Trópicos. Aí, finalmente, o etnólogo alcança o momento tão esperado. A viagem real cola-se pela primeira vez à viagem sonhada, supreendendo o viajante que ao reencontrar seus antecessores fecha um ciclo: "Não há perspectiva mais exaltante para o etnógrafo que a de ser o primeiro branco a penetrar numa comunidade indígena [...]. Eu revivia, pois, a experiência dos antigos viajantes [...]" (Lévi-Strauss 1957:346).

\section{De volta à França}

Lévi-Strauss permanece três anos no Brasil como professor na Universidade de São Paulo. Esse período é fundamental para o desenvolvimento de sua carreira futura. A partir dessa experiência, torna-se um americanista: inicia-se na prática etnográfica, expõe o material col etado em museus e galerias franceses, publica seus primeiros textos na área, integra a 
relação dos americanistas da Société, enfim, retorna à França reconhecido no meio etnológico como um profissional do ramo. Diz ele: “Um ano depois da visita aos Bororo, todas as condições para fazer de mim um etnógrafo estavam satisfeitas; benção de Lévy-Bruhl, de Mauss e de Rivet, retroativamente concedida; exposição de minhas coleções em uma galeria do bairro de Saint-Honoré; conferências e artigos" (Lévi-Strauss 1957:261).

O Brasil representou, portanto, um momento de passagem decisivo na construção de sua futura identidade profissional. Se antes de 1935, Lévi-Strauss era um professor de filosofia no ensino secundário francês com fortes vínculos com a política, a partir de 1938 transforma-se em um americanista com pesquisas sobre índios brasileiros, deixando a militância política de lado, ou melhor, a militância político-partidária, pois durante toda a sua vida manteve intensa atividade político-administrativa e acadêmica. Foi consel heiro cultural junto à embaixada francesa nos EUA, entre 1946 e 1948; ainda na América do Norte, funda com outros colegas a École Libre des Hautes Études; manteve-se ligado à UNESCO durante algum tempo; de volta a Paris depois da guerra, torna-se subdiretor do Musée de l'Homme; nos anos 60, cria o Laboratoire d'Anthropologie Sociale no Collège de France e a revista L'Homme.

Não apenas a carreira, mas também a obra de Lévi-Strauss é devedora da experiência brasileira. A primeira fase de sua produção apóia-se em matéria-prima obtida no Brasil, sobretudo o artigo sobre os Bororo e a tese sobre os Nambikwara, publicada em 1948, La Vie Familiale et Sociale des Indiens Nambikwara. Seus trabalhos posteriores, ainda que reúnam informações etnográficas de várias regiões americanas, foram também beneficiados pela etnografia brasileira, que funciona como uma espécie de ponto de partida a partir do qual a obra se projeta. Poderíamos dizer que a obra espiralar de Lévi-Strauss contém um movimento permanente que se traduz na incorporação de novos objetos e questões, e em um retorno sistemático a antigos resultados, ao começo - os Bororo, os N ambikwara. Basta olharmos os resumos de seus cursos - as paroles données - ao longo dos anos (Lévi-Strauss 1986). É exatamente nesse sentido a afirmação de Viveiros de Castro (1993:152):

“A experiência de Lévi-Strauss entre os Nambikwara é decisiva para o desenvolvimento da primeira parte do livro [As estruturas elementares do parentesco, SEP], que estabelece o princípio de reciprocidade e a ele remete o casamento bilateral. Os Nambikwara e os Tupi-Guarani já estavam na origem das primeiras reflexões do autor sobre o valor sociológico da afinidade 
e nas SEP aparecem exemplificando a forma mínima de troca matrimonial, o casamento avuncular".

Pensando nas ressonâncias de sua estada no meio intelectual paulista, não se pode afirmar que tenham sido fortes: além das já mencionadas colaborações em jornais e revistas de São Paulo, registra-se o seu engajamento discreto na Sociedade de Etnografia e Folclore. Sua entrada no Brasil ocorreu, de fato, a partir da década de 60 , com o reexame de tópicos como a organização dualista entre os povos do Brasil Central, no interior do projeto Harvard/Central Brazil (Maybury-Lewis 1979) e, anos depois, com os estudos do parentesco amazônico (Viveiros de Castro 1995).

O jovem agregé em filosofia, de perfil particular — não-francês, nãonormalista, judeu e militante socialista -, é indicado por Bouglé, durkheimiano fervoroso, para vir ao Brasil como professor. Em vários momentos, Lévi-Strauss afirma que a escolha de um aprendiz de etnologia avesso à tradição durkheimiana chocou-se de imediato com as intenções dos contratantes paulistas, imersos na influência comteana e durkheimiana, e que desejavam um professor de sociologia herdeiro dessa tradição:

“Fui para o Brasil porque queria ser etnólogo. Eu tinha sido conquistado pela etnologia em rebelião contra Durkheim, que não era um homem de campo, ao passo que eu descobria a etnologia de campo através dos ingleses e dos americanos. Eu estava portanto numa posição falsa. Chamaram-me para perpetuar a influência francesa, por um lado, e a tradição Comte-Durkheim, por outro. Eu estava conquistado naquele momento por uma etnologia de inspiração anglo-saxônica. Isto me criou uma série de dificuldades" (Eribon e Lévi-Strauss 1990:31).

Embora depoimentos de integrantes da missão francesa, assim como de ex-alunos da USP, também indiquem que boa parte das dificuldades de renovação do contrato de Lévi-Strauss deveu-se a esse descompasso de objetivos, outros apontam razões diferentes para os desentendimentos entre o professor e a Universidade, como, por exemplo, o interesse primordial de Lévi-Strauss pela pesquisa e o seu passado recente como militante de esquerda (Cardoso 1987). De fato, é preciso relativizar a oposição a Durkheim e a escolha da etnologia como "ato de rebelião" contra o sociólogo francês, tantas vezes enfatizada pelo próprio Lévi-Strauss. As afirmações referem-se a um contexto específico em que o jovem filósofo reclamava, dentre outras coisas, da ausência de trabalho de campo na 
escola sociológica francesa. Posteriormente, como bem sabemos, LéviStrauss não cansará de mencionar o seu débito intelectual em relação à produção durkheimiana e a dívida da etnologia para com a obra do mestre francês (Lévi-Strauss 1976).

Os problemas não existiam apenas entre os patrons da USP e os professores franceses, mas entre os próprios membros da missão. Além da inevitável competição entre jovens em início de carreira (Maugüé 1982:93-94; Eribon e Lévi-Strauss 1990:32), a posição privilegiada de Paul Arbousse-Bastide, que aspirava ser uma espécie de "chefe" do grupo, criou problemas extras para Lévi-Strauss, já que eram ambos professores da mesma disciplina (Cardoso 1987:189). Nas palavras de Lévi-Strauss: “Georges Dumas tinha empregado na Universidade, desde o primeiro ano, um jovem parente que era sociólogo. Quando cheguei, este quis colocar-me numa posição subordinada. Não fiquei satisfeito, e como resistisse, esforçou-se para que me despedissem em nome da tradição comteana, em que era especialista, e que meu ensino traía" (Eribon e LéviStrauss 1990:32). Com esta afirmação, Lévi-Strauss sugere que o argumento da exigência uspiana da fidelidade à tradição Comte-Durkheim foi acionado estrategicamente para encobrir outras razões; o que não quer dizer, evidentemente, que as afinidades entre certa elite intelectual paulista e a tradição durkheimiana não fosse verdadeira...

Em Saudades de São Paulo, Lévi-Strauss, mais uma vez, faz referência aos problemas envolvidos na não renovação de seu contrato com a USP. Nesse momento, retoma o argumento de Roger Bastide sobre as questões políticas envolvidas no episódio:

“Um colega francês, um pouco mais velho que eu e que me antecedera um ano na universidade, quis me colocar numa posição subordinada. Encontrou um ouvido complacente junto à direção de O Estado de S. Paulo, que tinha ascendência sobre a universidade. Eu não era o durkheimiano de estrita observância que desejavam; e minhas ligações com o M useu do Homem me designavam como próximo de seu diretor, o dr. Paul Rivet, reputado de extrema esquerda. Essa razão política, que não suspeitei enquanto estive no Brasil, soube-a bem mais tarde por um testemunho de meu sucessor na Universidade, Roger Bastide [...]. O fato é que quando renunciei a solicitar a renovação de meu contrato para me dedicar um ano a uma missão etnográfica e retornar em seguida à França, nenhum esforço foi feito para me reter" (LéviStrauss 1996:9-10). 
Quaisquer que tenham sido as razões "verdadeiras", o fato é que al gumas das dificuldades apontadas e o desejo de Lévi-Strauss de retomar a carreira universitária francesa, agora munido de rico material de pesquisa, concorreram para que o contrato padrão de três anos com a USP não fosse renovado. Assim, no começo de 1939, Lévi-Strauss e Dina deixavam o Brasil.

O exame do itinerário de Lévi-Strauss auxilia-nos a construir uma visão mais matizada do que foi a missão francesa dos anos 30, na recém-criada Universidade de São Paulo. Se, de fato, tivemos a importação de vários departamentos - dos alemães e italianos nas ciências físicas e matemáticas, aos franceses nas humanidades e letras - e, com os estrangeiros, as primeiras gerações formadas pela USP aprenderam a estudar, não devemos acreditar que aprenderam com todos, nem da mesma forma.

Os professores franceses, jovens iniciantes na docência e na pesquisa (sobretudo os que vieram antes da guerra, como J ean Maugüé, Claude Lévi-Strauss e Pierre M onbeig), ou com alguma experiência universitária, embora com obra e carreira ainda por construir, como Fernand Braudel e Roger Bastide, tiveram papel decisivo na formação intelectual de A ntonio Candido, Gilda de M ello e Souza, Décio de Almeida Prado, Florestan Fernandes, Lourival Gomes Machado, Ruy Coelho, M aria Isaura P. de Queiroz e de vários outros (Pontes 1996). Mas não podemos esquecer que as marcas por el es deixadas possuíam gradações diferenciadas, o que não poderia ser de outro modo, até porque a própria missão francesa era, antes de mais nada, heterogênea. Os diferentes professores estabel eceram nexos absolutamente distintos com o país. Se J ean M augüé e Roger Bastide foram responsáveis pela formação de nossa melhor intel ectualidade (Arantes 1994; Queiroz 1983), o mesmo não podemos dizer de Lévi-Strauss, de Fernand Braudel e de vários outros.

As diferentes disciplinas reagiram de modos distintos à presença estrangeira. Se a influência em alguns casos foi decisiva (J ean M aügué na filosofia, Roger Bastide na sociologia e Pierre Monbeig na geografia), em outros foi bastante discreta. A cadeira de antropologia adquiriu sotaques distintos no momento de sua criação. A voz francesa de timbre etnológico, dada por Lévi-Strauss, encontrou pouco eco perto de outras. As maiores influências na antropologia paulista naquele período eram: Donald Pierson, Emílio Willems, Herbert Baldus.

Institucionalmente, a antropologia surge na Universidade de São Paulo com a criação da cadeira de "Etnografia Brasileira e Língua Tupi" (1935) a cargo de Plínio Ayrosa, extinta em 1962. A cadeira de Antropo- 
logia, por sua vez, é criada em 1941, tendo como responsável Emílio Willems, substituído primeiro por Egon Schaden, em 1949, e este por J oão Batista Borges Pereira, em 1967 (Corrêa 1995a). Cabe ainda destacar a importância da Escola Livre de Sociologia e Política na formação de antropólogos no contexto paulista do período. Fundada em 1933 com o objetivo de preparar técnicos, a ênfase da ELSP, ao contrário da USP, era a pesquisa. Com a chegada de Donald Pierson em 1939 e a criação de uma seção de pós-graduação em 1941, a escola atrairá parte dos formandos da USP, como Florestan Fernandes, por exemplo (Limongi 1989; CarvaIho 1987).

Não parece exagerado afirmar que os primórdios da história da Universidade de São Paulo e a presença dos mestres estrangeiros em São Paulo na década de 30 reverberam até hoje nas feições adquiridas pelas ciências sociais em contexto paulista. A proeminência da sociologia na USP, primeiro com Roger Bastide e depois com Florestan Fernandes, é inegável. Inspirada no modelo durkheimiano, do qual a sociologia é a ciência síntese, a "escola paulista de sociologia" reuniu em torno dos estudos sociológicos, a ciência política e a antropologia. O caráter hegemônico do grupo de Florestan dificultou o desenvolvimento da ciência política e modelou a produção antropológica da instituição, tanto do ponto de vista teórico-metodológico, como também no que diz respeito ao elenco temático: estudos migratórios, a cidade de São Paulo, as relações raciais etc. (A rruda 1995:167-168). O mesmo parece ter ocorrido com a etnologia, cujo florescimento foi de certo modo obstaculizado pela preponderância da sociologia. Paradoxalmente, a etnologia foi introduzida nos cursos da USP por aquele que se tornaria o seu maior nome: LéviStrauss.

Recebido em 4 de novembro de 1996

Reapresentado em 5 de agosto de 1997

Aprovado em 24 de outubro de 1997

Fernanda Peixoto é professora de Antropologia na UNESP/Araraquara, colaboradora do CEBRAP e doutoranda em Antropologia Social na Universidade de São Paulo. É autora de artigos sobre a relação entre pensadores estrangeiros e as ciências sociais brasileiras. E-mail: fpeixoto@uol.com.br 


\section{Notas}

1 Destaco, dentre outras publicações, a série de entrevistas feitas por Didier Eribon, De Perto e de Longe (1990)[1988], onde, em pelo menos dois capítulos, Lévi-Strauss fala de sua estada no Brasil e Des Symboles et Leurs Doubles (1989), editado por ocasião da exposição realizada no Musée de l'Homme, "Les Amériques de Claude Lévi-Strauss", quando foram expostas várias peças recolhidas no Brasil. Das pesquisas realizadas, o projeto "História da Antropologia no Brasil (1930-1960)", coordenado por M ariza Corrêa, na Unicamp, sublinha a importância das andanças do antropólogo francês no Brasil e, sobretudo, a participação de Dina Lévi-Strauss nas instituições científicas e culturais da época. O trabalho de Grupioni (1995) acompanha as expedições do casal Lévi-Strauss e as coleções daí resultantes. O projeto "História das Ciências Sociais no Brasil", coordenado por Sérgio Miceli, no Idesp/SP, do qual se originou minha dissertação de mestrado (Peixoto Massi 1991), dedicou-se em vários momentos a pensar as marcas estrangeiras nas ciências sociais brasileiras. Cf. Miceli (1989; 1995) e Peixoto Massi e Pontes (1992).

O filme de Marcelo Tassara, O Brasil, os Índios e Finalmente a USP (1985), por sua vez, teve papel destacado na retomada dessa história. De lá para cá, em diversas ocasiões, no Brasil e na França, foram exibidos, também, os filmes feitos pelo casal Lévi-Strauss no Brasil. Ainda no campo dos registros visuais, lembro os dois volumes de fotografias, Saudades do Brasil (1994) e Saudades de São Paulo (1996), por intermédio dos quais é possível acompanhar os ângulos da lente de Lévi-Strauss. A reedição de Tristes Trópicos (1996) é mais um dado expressivo desse interesse renovado pelo Brasil de Lévi-Strauss.

2 Se é verdade que a etapa brasileira de Lévi-Strauss foi, durante muito tempo, deixada de lado pelos intérpretes, não é possível afirmar categoricamente o esquecimento de Lévi-Strauss em relação a ela; basta lembrarmos de Tristes Trópicos (1955), quando o autor se debruça mais detidamente sobre a sua experiência na USP e sobre as viagens realizadas em solo brasileiro.

3 É importante lembrar que se com o grupo durkheimiano, a etnologia adquire um novo estatuto institucional e intelectual, paralelamente, uma outra corrente continuava desenvolvendo um trabalho distinto na Escola de Antropologia e na Sociedade de Etnografia. A linha de tom mais durkheimiano e aquela afinada com essas duas instituições são antagônicas, não apenas do ponto de vista intelectual - enquanto a etnologia com os durkheimianos se aproxima da sociologia, a antropologia de Louis $M$ arin define-se como antropologia física - , mas também do ponto de vista político: o grupo durkheimiano identifica-se com os valores republicanos progressistas e com o socialismo, enquanto essa outra corrente adere aos valores reacionários da ordem social tradicional. Segundo alguns intérpretes, as sucessivas vitórias institucionais do grupo durkheimiano só foram possíveis graças à aproximação com os socialistas, que eram uma força política em ascensão (Lebovics 1988). 
4 A correpondência de Deborah Lifchitz e de Denise Paulme com Michel Leiris, em 1935, é um exemplo claro da dívida intelectual das pesquisadoras com Mauss e da importância de seus ensinamentos para a resolução de problemas colocados pela pesquisa (Dupuis 1987).

5 Os contatos de Paul Rivet (1876-1958) com a América do Sul datam do começo do século. O jovem médico militar conhece o Equador em 1901, quando é chamado a integrar uma missão francesa no país, lá permanecendo por cinco anos. Dessa experiência resulta Ethnographie A ncienne de l'Equateur (1912), em coautoria com Verneau. Esteve no Brasil diversas vezes e, dentre outras atividades, deu um curso na USP em 1952 sobre as origens do homem americano.

6 Eduardo Viveiros de Castro, em artigo retomando o seu percurso intelectual, esboça a paisagem americanista: "A antropologia se constituiu no século XIX a partir das realidades sócio-culturais da África, Oceania, Índia e América do Norte. A A mérica do Sul esteve à margem deste movimento sistemático de investigação sobre as formas não-européias de vida social, característico da modernidade tardia. O índio sul-americano foi o Selvagem da filosofia dos séculos XVI a XVIII, não o Primitivo da antropologia vitoriana [... ]. Assim, o americanismo deixou poucas marcas no acervo da disciplina" (Viveiros de Castro 1990:24-25). Sobre o americanismo, cf., também, Taylor (1984).

7 Georges Dumas (1886-1946), filósofo, médico e psicólogo francês, que muito contribuiu para o desenvolvimento da psicologia experimental na França, foi figura-chave na organização da vinda dos professores franceses para a Faculdade de Filosofia, Ciências e Letras da USP. J úlio de M esquita Filho encarrega Teodoro Ramos, matemático e professor da Escola Politécnica, de ir à Europa contratar professores. Seu itinerário de viagem é Itália, onde são escolhidos principalmente os matemáticos, e França, onde é Dumas - cujos primeiros contatos com o Brasil datam de 1907 - quem elege os nomes.

8 O primeiro grupo de professores franceses a desembarcar em solo paulista para iniciar as atividades da Faculdade de Filosofia, Ciências e Letras era composto pelo historiador Émile Coornaert, pelo geógrafo Pierre Deffontaines e pelo filósofo Etiènne Borne, que aqui permaneceram apenas um ano, de 1934 a 1935. Para uma análise mais detalhada dos diferentes perfis dos diversos grupos de professores que vieram para a Universidade de São Paulo e uma comparação com a missão francesa no Rio de J aneiro, cf. Peixoto Massi (1989) e Almeida (1989). Sobre Dina Lévi-Strauss, personagem hoje desconhecida, cf. Corrêa (1995b).

9 Ainda é Schaden quem lembra: “Eram os mais diversos assuntos discutidos por Lévi-Strauss em seus cursos. Além de teoria e metodologia sociológica e antropológica, em que o professor enveredava, inclusive, pelo arraial da antropologia física, discorrendo, por exemplo, sobre as técnicas da antropometria. Havia também outros cursos, semestrais, dedicados a campos mais restritos, tais como sociologia primitiva, o funcionalismo de Malinowski, o hiperdifusionismo de Elliot Smith, as teorias sobre totemismo segundo a análise crítica de Van Gennep. Depois 
de uma excursão ao norte do Paraná, onde conheceu Londrina, tomou a cidade como exemplo para analisar, durante um semestre, problemas sociológicos e antropológicos de planejamento urbano e urbanismo em geral" (Schaden 1984:254).

${ }^{10} \mathrm{~A}$ presença de Lowie na bibliografia é mais um indicador de sua influência sobre o jovem Lévi-Strauss. A leitura de Primitive Society, segundo LéviStrauss teria sido um dos fatores responsáveis pela sua decisão em tornar-se etnólogo (Eribon e Lévi-Strauss 1990:27). Já a inclusão de Durkheim, de certo modo, relativiza a afirmação feita em Tristes Trópicos, e em outras ocasiões, de que teria escolhido a etnologia contra o mestre francês. Voltarei a este ponto adiante.

11 Segundo algumas fontes, parece ter havido um texto imediatamente anterior, também sobre pintura moderna, publicado no segundo número da Revista Contemporânea, publicação que não foi possível localizar.

12 Sobre as afinidades existentes entre o projeto de Lévi-Strauss e a Sociedade de Etnografia e Folclore criada por M ário de Andrade no interior do Departamento de Cultura, em 1937, cf. Rubino (1995). A autora mostra que uma das diferenças existentes entre os projetos era que, ao contrário de Mário, Lévi-Strauss, inspirado na antropologia boasiana, não pretendia separar as pesquisas nas áreas física e cultural.

13Em 1942, já na França, ele envia mais um trabalho para a Revista do A rquivo M unicipal, “Guerra e Comércio entre os Índios da América do Sul”.

14Em carta a Paulo Duarte, de 3/4/1938, Mário de Andrade faz referência aos problemas ocasionados pelas viagens de Lévi-Strauss: “ $N$ ão estou fazendo nada a não ser as caceteações que tive com essas viagens etnográficas bestas do Lévi-Strauss e do Oto Leonardos. Estou perfeitamente de acordo que não se faça nada nesta última [....]. J á com o Lévi-Strauss, agora é tarde para voltar atrás. Chega amanhã aqui e conversarei com ele e o atirarei nas suas costas e nas do Sérgio. Se arranjem que preciso de sossego" (Duarte 1971:157).

15 É possível acompanhar essa primeira incursão ao campo pelo casal LéviStrauss através de quatro filmes feitos por eles e financiados pelo Departamento de Cultura de São Paulo. São filmes de oito minutos cada um, rodados em $16 \mathrm{~mm}$, entre dezembro de 1935 e janeiro de 1936, onde se encontram registrados aspectos da vida cotidiana das tribos visitadas no período. São eles: “A vida de uma aldeia bororo", "Cerimônias funerárias entre os bororo", “Aldeia de Nalike I" e “A Ideia de Nalike II".

16 M ostra Grupioni que a versão de Castro Faria não se confirma na leitura dos documentos do Conselho de Fiscalização das Expedições Artísticas e Científicas. Estes indicam as resistências existentes no SPI quanto à segurança da Missão e a relutância de Lévi-Strauss em aceitar um fiscal do Conselho. Nas palavras do autor: "Mais que a possível simpatia socialista identificada aos membros da expedição, era a perspectiva de fiscalização e controle de uma expedição estrangeira, o que teria impedido a concessão da licença" (1995:76). 


\section{Referências bibliográficas}

ALMEIDA, M aria Hermínia T. de. 1989. “Dilemas da Institucionalização das Ciências Sociais no Rio de J aneiro". In: S. Miceli (org.), História das Ciências Sociais no Brasil (vol.1). São Paulo: Vértice/Idesp/Finep. pp. 188-216.

ARANTES, Paulo E. 1994. Um Departamento Francês de Ultramar - Estudos sobre a Formação da Cultura Filosófica Uspiana. Rio de J aneiro: Paz e Terra.

ARRUDA, M aria Arminda do N. 1995.

"A Sociologia no Brasil: Florestan Fernandes e a 'Escola Paulista'”. In: S. Miceli (org.), História das Ciências Sociais no Brasil (vol. 2). São Paulo: Editora Sumaré. pp. 107-232.

CALTAGIRONE, Benedetto. 1988. “Le Séjour en Ethiopie de la Mission Dakar-Djibouti". Gradhiva, 5:3-12.

CARDOSO, Irene. 1987. "Entrevista com Roger Bastide". Discurso, 16:181197.

CARVALHO, N. Valadares (org.). 1987. Leituras Sociológicas. São Paulo: Vértice.

CLASTRES, Helène. 1983. “Primitivismo e Ciências do Homem no Século XVIII". Discurso, 13:187-208.

CLIFFORD, James. 1981. "On Ethnographic Surrealism". Comparative Studies of Society and History, 23(4):539-564.

.1988. "Power and Dialogue in Ethnography: Marcel Griaule's Initiation". In: The Predicament of Culture. Cambridge: Harvard University Press. pp. 55-91.

CORRÊA, Mariza. 1995a. “A Antropologia no Brasil (1960-1980)". In: S. Miceli (org.), História das Ciências
Sociais no Brasil (vol. 2). São Paulo: Editora Sumaré. pp. 25-106.

.1995b. “A Natureza Imaginária do Gênero na História da Antropologia". Cadernos Pagu, 5:109-130.

CUISINIER, J ean e SEGALEN, Martine. 1986. Ethnologie de la France. Paris: PUF.

DUARTE, Paulo. 1971. Mário de Andrade por Ele Mesmo. São Paulo: Edart. DUCHET, M ichèle. 1977. Anthropologie et Histoire aux Siècles des Lumières. Paris: Flammarion.

DUPUIS, Annie. 1987. “Correspondance de Deborah Lifchitz et Denise Paulme avec Michel Leiris, Sanga, 1935". Gradhiva, 3:44-58.

ERIBON, Didier e LÉVI-STRAUSS, Claude. 1990 [1988]. De Perto e de Longe. Rio de J aneiro: Nova Fronteira.

FARIA, Luis de Castro. 1984. "A Antropologia no Brasil: Depoimento sem Compromisso de um M ilitante em Recesso". Anuário Antropológico 82. Brasília: Tempo Brasileiro. pp. 228-250.

GRUPIONI, Luis Donisete B. 1995. Coleções e Expedições Vigiadas - $\mathrm{O}$ Caso Nimuendaju e o Caso LéviStrauss no Conselho de Fiscalização das Expedições Artísticas e Científicas no Brasil. Cebrap. Mimeo.

J AMIN, J ean e PRICE, Sally. 1988. “Entretien avec Michel Leiris". Gradhiva, 4:28-56.

JAMIN, J ean e COPANS, J. 1994. Aux Origines de I'Anthropologie Française - Les M émoires de la Société des Observateurs de I'Homme en an VIII. Paris: J ean Michel Place. KARADY, Victor. 1988. “Durkheim et les Débuts de I'Ethnologie Univer- 
sitaire". Actes de la Recherche en Sciences Sociales, 74:23-32.

LEBOVICS, Herman. 1988. “Le Conservantisme en Anthropologie et la Fin de la Troisième République". Gradhiva, 4:3-16.

LÉVI-STRAUSS, Claude. 1935a. “O Cubismo e a Vida Cotidiana". Revista do Arquivo Municipal, 2(18):241245.

.1935b. "Em Prol de um Instituto de Antropologia Física e Cultural". Revista do Arquivo Municipal, 2(18):247-263.

. 1936. "Contribuição para o Estudo da Organização Social Bororo". Revista do Arquivo Municipal, 3(27):8-79.

. 1937. “A Propósito da Civilização Chaco-Santiaguense". Revista do Arquivo Municipal, 4(42):5-21. . 1942. “Guerra e Comércio entre os Índios da A mérica do Sul". Revista do Arquivo Municipal, 8(87): 131-146.

. 1957 [1955].Tristes Trópicos. São Paulo: Anhembi.

. 1976 [1958]. “O que a Etnologia Deve a Durkheim”. In: Antropologia Estrutural II. Rio de J aneiro: Tempo Brasileiro. pp. 52-56.

. 1986 [1984]. Palavras Dadas. São Paulo: Brasiliense.

. 1989. Des Symboles et Leurs Doubles. Paris: Plon.

.1994. Saudades do Brasil. São Paulo: Cia. das Letras. . 1996. Saudades de São Paulo. São Paulo: Cia. das Letras.

LIM ONGI, Fernando P. 1989. “A Escola Livre de Sociologia e Política em São Paulo". In: S. Miceli (org.), História das Ciências Sociais no Brasil (vol. 1). São Paulo: Vértice/Idesp/ Finep. pp. 217-233.

LINDON, Mathieu. 1988. “Mission Tristes Tropiques". Libération, 1, setembro.

MAUGÜÉ, J ean. 1982. Les Dents Agacées. Paris: Buchet-Chastel.

MAYBURY-LEWIS, David (ed.). 1979. Dialectical Societies, the Gê and Bororo, Brazil. Cambridge/London: Harvard University Press.

MAZON, Brigitte. 1985. “La Fondation Rockfeller et les Sciences Sociales en France, 1925-1940". Revue Française de Sociologie, 26(2):311-341.

MELLO E SOUZA, Antonio C. de. 1988. Depoimento ao projeto “História das Ciências Sociais no Brasil (1930-1969)". Idesp. M imeo.

MELLO E SOUZA, Gilda de. 1990. Exercícios de Leitura. São Paulo: Duas Cidades.

MICELI, Sérgio (org.). 1989. História das Ciências Sociais no Brasil (vol. 1). São Paulo: Vértice/Idesp/Finep. . 1995. História das Ciências Sociais no Brasil (vol. 2). São Paulo: Editora Sumaré.

MORAES, Eliane Robert. 1996. Retrato Impossível - O Corpo Desfigurado no Modernismo Francês. Tese de Doutorado, Departamento de Filosofia/USP.

PEIXOTO MASSI, Fernanda. 1989. "Franceses e Norte-Americanos nas Ciências Sociais Brasileiras (1930-1960)". In: S. Miceli (org.), História das Ciências Sociais no Brasil (vol. 1). São Paulo: Vértice/ Idesp/Finep. pp. 410-459. . 1991. Estrangeiros no Brasil - A M issão Francesa na Universidade de São Paulo. Dissertação de Mes- 
trado, Departamento de Antropologia/Unicamp.

. 1992. "O Nativo e o Narrativo Os Trópicos de Lévi-Strauss e a África de Michel Leiris". Novos Estudos Cebrap, 33:187-198.

e PONTES, Heloisa. 1992. Guia Biobibliográfico dos Brasilianistas. São Paulo: Sumaré.

PONTES, Heloisa. 1996. Destinos M istos: O Grupo Clima no Sistema Cultural Paulista (1940-1968). Tese de Doutorado, Departamento de Sociologia/USP.

PRADO, Décio de Almeida. 1997. "Saudades de Lévi-Strauss". In: Seres, Coisas, Lugares. São Paulo: Cia. das Letras.

QUEIROZ, Maria Isaura P. de. 1983. “N ostalgia do Outro e do Alhures: A Obra Sociológica de Roger Bastide". In: Roger Bastide. São Paulo: Ática. pp. 7-77.

RIVET, Paul. 1940. “A Etnologia em França". Revista do Arquivo M unicipal, 66(6):25-41.

RUBINO, Silvana. 1995. “Clube de Pesquisadores. A Sociedade de Etnografia e Folclore e a Sociedade de Sociologia". In: S. Miceli (org.), História das Ciências Sociais no Brasil (vol. 2). São Paulo: Editora Sumaré. pp. 479-522.

SCHADEN, Egon. 1984. “Os Primeiros Tempos da Antropologia em São PauIo". A nuário A ntropológico 82. Brasília: Tempo Brasileiro. pp. 251-258. .1990. Depoimento concedido à autora.

SOARES, Lélia G. 1983. Mário de Andrade e a Sociedade de Etnografia e Folclore, no Departamento de Cultura da Prefeitura Municipal de São Paulo, 1936-1939. Rio de J aneiro/ São Paulo: Funarte/Instituto N acional do Folclore/Secretaria M unicipal da Cultura.
TAYLOR, A nne-Christine. 1984. “L'Americanisme Tropical, une Frontière Fossile de l'Ethnologie?" In: B. Rupp-Eisenreich (org.), Histoires de I'A nthropologie (XVI-XIX Siècles). Paris: Klincksieck. pp. 213-233.

VIVEIROS DE CASTRO, Eduardo. 1990. O Campo na Selva Visto da Praia (Fazendo Etnologia Indígena no Museu Nacional, 1974-90). TrabaIho apresentado no XIV Encontro Anual da Anpocs, Caxambu, MG. . 1993. "Alguns Aspectos da A finidade no Dravidianato Amazônico". In: M. Carneiro da Cunha e E. Viveiros de Castro (orgs.), A mazônia - Etnologia e História Indígena. São Paulo: FAPESP/NHII-USP. (org.). 1995. Antropologia do Parentesco. Estudos Ameríndios. Rio de J aneiro: Editora da UFRJ . 


\section{Resumo}

O artigo procura acompanhar o período brasileiro de Claude Lévi-Strauss (1935-1938), rastreando suas publicações, aulas e pesquisas no momento em que era professor de sociologia na Universidade de São Paulo, com o objetivo de compreender o lugar ocupado pelo Brasil na sua trajetória. O interesse é mostrar que apesar de breve, e de modo geral silenciada, a etapa brasileira do autor foi fundamental para os desdobramentos de sua futura carreira como etnólogo e americanista. O texto procura também avaliar o significado da vinda de Lévi-Strauss para o Brasil no contexto francês da época, quando o americanismo era ainda terreno pouco explorado, ao contrário do africanismo, “vocação" em voga no momento.

\section{Abstract}

This article analyzes the Brazilian period of Claude Lévi-Strauss (1935-1938), tracing his publications, classes, and research during the time in which he was a professor of sociology at the Universidade de São Paulo in order to better understand the place Brazil occupied in his intellectual itinerary. The purpose is to show that although this period was brief (and largely silenced), it was crucial to subsequent developments in the author's career as ethnologist and Americanist. The text also assesses the significance of Lévi-Strauss' coming to Brazil in the French context of the time, when A mericanism was a scarcely explored terrain, contrary to Africanism, a "calling" then in vogue. 